\title{
Hypoglycaemia - its causes and symptoms in the population of developmental age
}

\author{
Ewa Otto-Buczkowska', Natalia Jainta², Karolina Grzyb² \\ ${ }^{1}$ Medical Specialist Centre in Gliwice, Poland \\ ${ }^{2}$ Medical University of Silesia in Katowice, Poland
}

\section{ABSTRACT}

The amount of glucose in the circulation depends on its absorption from the intestine, uptake and release from the liver, and uptake by peripheral tissues. Insulin and glucagon together control the rate of metabolism required by peripheral tissues, and both are involved in maintaining glucose homeostasis. Insulin is considered to be an anabolic hormone that promotes the synthesis of protein, lipid, and glycogen. The key target tissues of insulin are: liver, muscle, and adipose tissue. Glucagon notably affects catabolic processes. Glucose is essential for cerebral metabolism. Unsurprisingly therefore, hypoglycaemia may result in encephalopathy. Knowledge of the homeostatic mechanisms that maintain blood glucose concentrations within a tight range is the key for diagnosis and appropriate management of hypoglycaemia. Young age, fasting, and severe infectious diseases are considered as important risk factors. Failure in investigating a neonate, infant, or a child with suspicion of hypoglycaemia, increases the risk of delaying a definitive diagnosis and instituting effective treatment. Expeditious identifying the specific cause of hypoglycaemia, as outlined above, will enable accurate institution of appropriate treatment and decrease the risk of permanent brain injury from persistent and recurrent severe hypoglycaemia. Prompt diagnosis with aggressive early intervention remains the mainstay of treatment to avert irreversible brain damage.

\section{KEY WORDS:}

glucose homeostasis, glucose production, glucose utilisation, hormonal regulation of carbohydrate metabolism, pancreatic hormones, insulin, glucagon, gastrointestinal hormones.

\section{INTRODUCTION}

Glucose plays an essential role in the metabolic homeostasis of the body. Its homeostasis is the result of the blood glucose supply and consumption. Maintaining the balance between glucose production and its consumption is primarily determined by two pancreatic hormones: insulin and its antagonist, glucagon, but a number of other factors are involved in this regulation. The level of glucose in the circulation depends on its absorption in the intestines, production in the liver and kidneys, and its tissue consumption. Glucose is delivered to the blood from two sources: from the gastrointestinal tract and from the liver and kidneys (glycogenolysis and gluconeogenesis) [1]. Hypoglycaemia is a syndrome of symptoms, associated with a decrease in blood glucose levels, which subside following glucose administration. Hypoglycaemia, which may be transient, persistent, or recurrent, is associated with many conditions [2].

\section{ADDRESS FOR CORRESPONDENCE:}

Natalia Jainta, Medical University of Silesia, 15 Poniatowskiego St, 40-055 Katowice, Poland,

e-mail: nataliajainta@gmail.com 


\section{MECHANISMS OF GLUCOSE HOMEOSTASIS REGULATION}

\section{METABOLIC PHENOMENA}

Glycolysis - this is the process of glucose oxidation, the main pathway of glucose catabolism; it runs in all cells. It can be conducted both in aerobic and anaerobic conditions. An oxygen-induced change leads to the formation of pyruvate, which then enters the citric acid cycle (Krebs tricarboxylic acid cycle). This cycle is a common end point for the oxidation of carbohydrates, lipids, and proteins.

Gluconeogenesis - this process converts non-carbohydrate compounds into glucose. It is mainly present in the liver and partly in the kidneys [3]. The main substrates for gluconeogenesis are lactate, pyruvate amino acid glucose, and glycerol. The next step in carbohydrate metabolism is the metabolism of glycogen. Synthesis of glycogen from substrates of gluconeogenesis is termed glycogenogenesis. Glycogen degradation (glycogenolysis) is intended to safeguard normal blood glucose levels.

\section{HORMONES REGULATING THE CELLULAR USE OF GLUCOSE}

Pancreatic hormones - the most important metabolic value belongs to insulin and its main antagonist, glucagon.

Insulin is one of the most important anabolic hormones in the body. It is synthesised in $\beta$-cells of the "island organ" of the pancreas. Insulin affects glucose metabolism both directly by increasing glucose transport, stimulating glycolysis and glycogen synthesis, and indirectly by blocking the delivery of substrates for glucose resynthesis. The metabolism of glucose is also regulated by insulin within the cells.

Glucagon is the second most important hormone to maintain glucose homeostasis. It is produced by pancreatic a-cells. Glucagon is the most important catabolic hormone, which mainly acts on the liver, stimulating glycogenolysis and gluconeogenesis and inhibiting glycogenogenesis and glycolysis; its effects increase hepatic glucose production (HGP). It plays a crucial role in ensuring that glucose delivery from the liver is adequate for the current needs of the body. Glucagon not only protects the body against hypoglycaemia, but also restores normoglycaemia if hypoglycaemia has occurred. Within the Langerhans islands, it also has an incretin effect that affects the secretion of insulin and somatostatin. Among pancreatic hormones that play a role in glucose metabolism, somatostatin, pancreatic polypeptide, and islet amyloid polypeptide should also be mentioned. Gastrointestinal hormones constitute one of the poles of the intestinal-pancreas axis. Not only are they crucial for the maintenance of glucose homeostasis, but also they affect the secretion of digestive enzymes, regulate gastrointestinal motility, and have an incretin effect on the secretion of insulin and glucagon.

\section{OTHER MECHANISMS OF GLUCOSE HOMEOSTASIS REGULATION}

Hormones affecting the secretion of digestive enzymes, as well as hormones regulating the gastrointestinal motility, must be listed here. The hypothalamic-pituitary-adrenal axis (HPA) is also an important factor in glucose homeostasis.

\section{HYPOGLYCAEMIA - ITS CAUSES WAND SYMPTOMS}

Hypoglycaemia is a syndrome of symptoms associated with a decrease in blood glucose levels, which subsides following glucose administration. The first reports appeared in the 1930s [3]. This knowledge deepened in subsequent years [4]. Hypoglycaemia, which may be transient, persistent, or recurrent, is associated with many conditions [5-9].

\section{RECOGNITION OF HYPOGLYCAEMIA}

Borderline blood glucose levels, which supply brain tissue in energy, should be assessed in terms of age, taking into account the technique of collection and the method of determination and the presence of, for example, polytomies $[10,11]$. It is assumed that blood glucose levels measured in whole blood are $15 \%$ lower than those determined in plasma, due to the relatively low concentration of glucose in red blood cells. The blood glucose concentration measured in venous blood is $10 \%$ lower than in capillary or arterial blood. Newborns have the lowest prevalence at $1.7 \mathrm{mmol} / \mathrm{l}(30 \mathrm{mg} / \mathrm{dl})$, and in prematures $1.1 \mathrm{mmol} / \mathrm{l}(20 \mathrm{mg} / \mathrm{dl})$, in the first three days of life. Infants can range from 2.2 to $2.8 \mathrm{mmol} / \mathrm{l}(40-50 \mathrm{mg} / \mathrm{dl})$, and in adults and older children the borderline of the limit value is specified as $3.0 \mathrm{mmol} / \mathrm{l}(54 \mathrm{mg} / \mathrm{dl})$. Slightly different values were presented by Faustino et al. They suggest defining hypoglycaemia as $<2.2-2.5 \mathrm{mmol} / \mathrm{l}(<40-45 \mathrm{mg} / \mathrm{dl})$ in neonates and $<3.3-3.6 \mathrm{mmol} / \mathrm{l}(<60-65 \mathrm{mg} / \mathrm{dl})$ in children [12]. Commonly accepted severe hypoglycaemia is defined as blood glucose $<2.2 \mathrm{mmol} / \mathrm{l}(<40 \mathrm{mg} / \mathrm{dl})$.

\section{DISORDERS OF GLUCOSE HOMEOSTASIS IN NEWBORNS AND YOUNG INFANTS}

The issue of blood glucose assessment in neonates and young infants raises a number of controversies. Adamkin et al., on behalf of the Committee on Foetuses and Newborns, presented a practical guide and algorithm for the screening and subsequent management of neonatal hypoglycaemia [13]. Neonatal hypoglycaemia is common; however, there is ongoing controversy regarding 
its operational definition. Recently recommended values are significantly higher. The most recent published survey of British neonatologists showed wide variation in definitions of neonatal hypoglycaemia from $<1$ to $<4 \mathrm{mmol} / \mathrm{l}$ (18-72 $\mathrm{mg} / \mathrm{dl})$ [14]. In the healthy neonate, immediately after birth, lower blood glucose values are common. These transiently lower glucose values, improve, and reach normal ranges within hours after birth. It is assumed that the transient form of hypoglycaemia will last up to 48 hours; if it persists longer, it should be regarded as pathological [15]. The subject of discussion is when the concentration glucose is considered to be normal and when it is already hypoglycaemia. The test results of glucose depend on many factors. These include the technique of the study performed, the type of blood from which the test was performed (venous, capillary, arterial, or serum), and the method [16-18]. Recently, continuous recording is being used to monitor glycaemia also in children (continuous glucose monitoring sensor - CGMS) [19-23]. The real-time continuous glucose monitoring in combination with proportional integral derivative control can reduce hypoglycaemia during tight glycaemic control [24]. Factors such as elapsed time from childbirth, course of birth (hypoxia etc.), body weight (large for gestational age - LGA, small for gestational age - SGA), and maternal facts (medications, glucose infusion, etc.) are also of great importance [25-29].

Significant differences occurred in the group of 180 children hospitalised in the neonatal unit and followed-up by Hussain and Sharief [30]. Serum glucose levels should be considered to be in the range $2.8-5.6 \mathrm{mmol} / \mathrm{l}$ $(50-100 \mathrm{mg} / \mathrm{dl})$ in neonates receiving no intravenous infusion. Glucose determinations should be made by laboratory methods in venous blood serum; a glucometer may be useful for the screening test, but the results should be verified by laboratory methods [31,32]. Glucose testing should be performed routinely in sick children as well as prematures [33].

In neonates not at risk of glucose metabolism disorders, blood glucose should be measured between one and four hours postnatally and repeated between eight and 16 hours of life unless there are indications for a previous study (e.g. symptoms of hypoglycaemia). Newborns from high-risk groups receiving constant IV fluid infusions should have blood glucose determined at each connection for the first three days and then once a day for 4-7 days after birth. In non-high-risk infants receiving infusion fluids, glycaemia should be measured 1-2 times a day for the first week of life. In infants receiving IV fluids, with concentration of glucose in the blood within the normal range, the frequency of testing can be reduced to two times per week.

Schaefer-Graf et al. [34], who conducted a number of studies in 1136 newborn infants born with greater than normal body weight (LGA), recommend routine glucose determination in this group. The authors believe that newborns whose mothers had glucose levels $10.0 \mathrm{mmol} / \mathrm{l}$ ( $\geq 180 \mathrm{mg} / \mathrm{dl}$ ) during a one-hour oral glucose tolerance test, have an increased risk of hypoglycaemia.

\section{CLINICAL PICTURE OF HYPOGLYCAEMIA AND ITS BASIS IN ACCORDANCE WITH AGE}

Hypoglycaemia is most prevalent in the neonatal period, in early infancy, and in children between two and eight years of age; it is less common in older children. The causes of hypoglycaemia are generally divided into permanent and transient. Symptoms of hypoglycaemia can be varied and may occur in different combinations and in varying degrees, not always strictly dependent on the absolute values of the glycaemia. Hypoglycaemia, especially in newborns, infants, and young children, should always be treated as a state of emergency because it can lead to short-term death if not fatal, in any case to very serious permanent central nervous system damage [35]. Early diagnosis and aggressive treatment is crucial. Symptomatic treatment should be implemented immediately and continued until normoglycaemia is stabilised, independently of the simultaneous diagnosis. In newborns, the occurrence of hypoglycaemia is often associated with low gestational age. Stomnaroska et al. investigated 84 patients who were found to have hypoglycaemia; in this group $89.25 \%$ of babies were premature [36]. According to the authors, however, further studies on a larger population are necessary to fully understand and prevent the phenomenon of hypoglycaemia in newborns. In children after the neonatal period the most common causes of hypoglycaemia are diabetes mellitus and idiopathic ketotic hypoglycaemia (IKH), but a number of endocrine disorders and inborn errors of metabolism (IEMs) need to be excluded [37].

Hypoglycaemia may be caused by increased glucose consumption or decreased glucose production. This condition can be divided into the following: hypoglycaemia with accompanying hyperinsulinaemia and hypoglycaemia with normoinsulinaemia or even hypoinsulinaemia. An important element in differentiating hypoglycaemia is the presence or absence of ketose (hyperketotic and hypoketotic hypoglycaemia). Genetic activation of the insulin signal-transducing kinase AKT2 causes syndromic hypoketotic hypoglycaemia without elevated insulin [38]. Increased glucose consumption may be due to hyperinsulinism [39]. Pancreatic $\beta$-cells are functionally programmed to release insulin in response to changes in plasma glucose concentration. A number of already identified genetic defects may result in dysregulation of insulin secretion, leading to severe hypoglycaemia. Such defects may affect receptors located not only in $\beta$-cells but also in $\alpha$-cells, which may cause insufficient secretion of glucagon in these states [40]. Also, a number of other genetic mutations may be responsible for the occurrence of hypoglycaemic conditions. In hyperinsulinaemic hyperglycaemia, insulin secretion becomes dysregulated, so 
that it persists even in the presence of low plasma glucose concentrations [41-43]. Recent international agreements have been presented on congenital hypoglycaemia disorders, emphasising novel molecular mechanisms resulting in genetic diagnosis and new therapies [44].

Hyperinsulinaemia can be transient or persistent [45, 46]. It is the most common cause of hypoglycaemia in the first three months of life. Transient neonatal hyperinsulinaemia may be associated with intrauterine hypoxia or low body mass. It is well known in children of diabetic mothers [47, 48]. Congenital hyperinsulinism is a condition leading to recurrent hypoglycaemia due to inappropriate insulin secretion by pancreatic islet beta cells [49-51]. Is it usually isolated, but may rarely be part of a genetic syndrome [52-55]. A discussion, based on the literature, that showed the usefulness of the study of various forms of hyperinsulinaemic hypoglycaemia, involving defects in key genes regulating insulin secretion, was presented by Vora et al. [56]. Two types of hyperinsulinaemia can be distinguished: diffused (70\% of cases) and focal (30\% of cases).

Insulinoma is a very rare tumour in children and adolescents. In children, pancreatic insulinomas are usually solitary and benign tumours. Prompt and early diagnosis of insulinoma is essential because it can trigger recurrent hypoglycaemia, which can lead to irreversible neurological damage. Most insulinomas in children are benign and so can be treated successfully by surgical resection [5759]. One form of hyperinsulinaemic - hypoglycaemia is familial hyperinsulinism (FHI). It is caused by a gene mutation. An extensive discussion of FHI was presented by Glaser [60], who drew attention to differences in the course of the disease depending on the age at which it occurred. Neonatal-onset disease manifests within hours to two days after birth. Childhood-onset disease manifests during the first months or years of life. In the newborn, FHI is characterised by a severe course.

Hyperinsulinaemia associated with hyperplasia of pancreatic islets of Langerhans may be related to some other medical disorders [61]. De Lonlay et al. observed a group of 175 patients with hypoglycaemia for over 20 years. In 98 cases, the symptoms occurred during the neonatal period, amongst 12 patients being transient, while 86 patients were diagnosed with persistent hyperinsulinaemia [62]. Neonates were clinically more severely affected than infants. Neonates required higher rates of IV glucose than infants, to maintain normal plasma glucose levels (16 mg/kg per min vs. $12 \mathrm{mg} / \mathrm{kg}$ per min). Eight of nine patients with childhood onset of hyperinsulinism were treated surgically, and histological examination confirmed an adenoma in each case. It is interesting to report the occurrence of hyperinsulinaemic hypoglycaemia in neonates from families with MODY-associated diabetes mellitus with mutation in the HNF4A gene [63].

The endocrine system plays the key role in regulation of glucose homeostasis, particularly emphasising the hy- pothalamic-pituitary-adrenal axis hormones. Amongst hormonal causes, hypothalamic-pituitary insufficiency should undoubtedly be mentioned, in the course of which the deficit of hormones from anterior lobe of pituitary gland may occur $[64,65]$. Secretion disorders may concern selectively single hormones or several hormones at the same time: growth hormone $(\mathrm{GH})$, corticotropin (ACTH), thyrotropin hormone (TSH), as well as gonadotrophins (FSH, LH). Reasons for defects in pituitary gland hormone secretion may apply to the hypophysis itself, but they can also follow disturbances in secretion of releasing hormones in the hypothalamus.

Statement during the episodes of hypoglycaemia reduced in the blood serum levels of insulin, free thyroxine, thyroid-stimulating hormone, and growth hormone, suggesting a diagnosis of hypopituitarism and requiring further diagnostics. Extensive coverage of endocrine causes of hypoglycaemia in childhood has been recently reported by Sreekantam et al. [66].

The deficit of secretion may have a genetic basis or be related to some malformations. Another reason of hormonal hypoglycaemia is glucocorticoid deficiency. A shortage of adrenal hormone secretion leads to a decrease in hepatic gluconeogenesis and finally to hypoglycaemia $[64,67]$. A lot of facts indicate that the occurrence of hypoglycaemia among children with congenital hyperinsulinism is caused not only by increased insulin secretion, but also that glucagon's release shortage (which is the strongest contra-regulatory hormone) might play a role [68].

An interesting analysis of hormonal response to hypoglycaemia was conducted by Crofton and Midgley [69]. They analysed two groups of children: one with 16 infants below the $3^{\text {rd }}$ month of life and a second group with 14 infants and children up to the $4^{\text {th }}$ year of life. In the first group, infants with hyperinsulinaemia prevailed, while in the second one the causes of hypoglycaemia were more diverse. Age-dependency affected the secretion of cortisone and growth hormone in the course of hypoglycaemia. The authors claimed that cortisone secretion measurement is more reliable for pituitary gland and adrenal gland function assessment among older vs. younger children.

\section{INHERITED METABOLIC DISORDERS AS THE CAUSE OF HYPOGLYCAEMIA IN NEONATES AND INFANTS}

One of the best known congenital metabolic disorders associated with hypoglycaemia are glycogen storage diseases (GSD). Hypoglycaemia is also a common phenomenon in the case of fatty acid oxidation block. The most frequent defect of oxidation is medium-chain acyl-CoA dehydrogenase (MCAD) deficiency.

Glycogen metabolism disorders - among the best known congenital metabolic defects associated with hy- 
poglycaemia are glycogen storage diseases (GSD) [70], a group of hereditary disorders characterised by accumulation of pathological type or inappropriate amounts of glycogen in tissues [71-73].

Defects leading to these disorders can be heterogenous $[74,75]$. In the therapy of GSD, dietetic treatment plays a crucial role for the prevention of hypoglycaemic episodes [76, 77].

\section{DISORDERS OF GLUCONEOGENESIS}

The cause of gluconeogenesis reduction is either shortage of substrates or enzymatic blocks. Enzymatic defects manifest primarily as a deficiency of fructose-1,6-bisphosphatase (FBPase). Fructose-1,6-bisphosphatase deficiency is an autosomal, recessively inherited disease that progresses with severe hypoglycaemia and metabolic attacks resulting from the defect in gluconeogenesis [78-80]. Fructose-1,6-bisphosphatase deficiency was first described in 1970 [81]. Among causes of reduction of gluconeogenesis can be distinguished both the excess of insulin that inhibits gluconeogenesis and the deficiency of hormones that have antagonistic effects on insulin [82].

\section{DISORDERS OF KETOGENESIS AND KETONE USE}

Idiopathic ketotic hypoglycaemia $(\mathrm{KH})$ is the most common form of-hypoglycaemia beyond infancy. It was first described 50 years ago [83]. Such a form of hypoglycaemia rarely appears before the $18^{\text {th }}$ month of life. Pathophysiology of hypoglycaemia in idiopathic KH is not explained. It is thought that hypoglycaemia in $\mathrm{KH}$ is caused by an inability to sustain adequate rates of endogenous glucose production (EGP) during fasting along with the higher glucose requirement in young children. The decrease in glycogenolysis (GGL) is not accompanied by a significant increase in gluconeogenesis (GNG), possibly because of a limitation in the supply of alanine [84]. The cause of severe hypoglycaemia may also be connected with hypersensitivity to leucine. Studies by Bodamer et al. indicate that energy demand is significantly increased, whereas leucine oxidation is reduced [85]. Idiopathic ketotic hypoglycaemia is the most common cause of hypoglycaemia in toddlers. Diagnosis is important for preventing serious, long-term sequelae, and therefore checking urine and blood ketones is an essential part of the evaluation in any hypoglycaemic toddler [86]. The frequency of this form of hypoglycaemia among children accessed to an intensive care unit is highlighted by Daly et al. [87].

\section{FATTY-ACID OXIDATION DISORDERS}

Hypoglycaemia is also a common occurrence in fatty acid oxidation blocks. Medium-chain acyl-coenzyme A dehydrogenase deficiency (MCADD) is a disorder of fatty acid $\beta$-oxidation inherited in an autosomal recessive manner. This may be the cause of hypoketotic hypoglycaemia in a child [88-90]. Fasting hypoketotic hypoglycaemia without hyperinsulinaemia should lead to suspicion of fatty acid oxidation defect. The inability to use fats as a source of energy enhances the risk of life-threatening episodes that can lead to sudden death.

\section{HYPOGLYCAEMIA ASSOCIATED WITH DIFFERENT DISORDERS}

In older infants, children, and adolescents, besides metabolic blocks, the cause of hypoglycaemia can also be related to liver disturbance, generalised disease, or poisoning. Alteration of blood glucose homeostasis is frequent in critically ill children. Considerable alterations of glucose metabolism are found in critical states associated with stress factors such as trauma, major surgery, or sepsis. Prolonged stress is characterised by progression of metabolic deregulation, in which gluconeogenesis shows resistance to the inhibiting actions of insulin and glucose. This resistance refers not only to the insulin influence on glucose homeostasis, but stress is associated also with resistance to other insulin effects such as lipolysis suppression [91-93].

\section{DIAGNOSIS OF HYPOGLYCAEMIA}

In the first hours of a newborn's life, hypoglycaemia may have no symptoms or they can be non-specific [33]. Many authors believe that the determination of neonatal blood glucose should be performed routinely. The scope of diagnostic tests and the timing of their implementation depends on the current capabilities.

Preliminary laboratory tests [94, 95]:

- blood glucose level measurement - pH of blood (detecting the acidosis),

- electrolytes,

- ammonia level in the blood,

- ketones in blood and urine,

- insulin serum level - if glycaemia is less than $2.2 \mathrm{mmol} / \mathrm{l}$ (40 mg/dl), the insulin level measured in the serum should not exceed 5-6 $\mu \mathrm{U} / \mathrm{ml}$, and values exceeding $10 \mu \mathrm{U} / \mathrm{ml}$ indicate hyperinsulinaemia,

- other hormones levels (growth hormone, cortisol),

- amino acids in blood and urine,

- lactate serum levels,

- organic acids in urine.

Further tests depend on requirements and possibilities.

Diagnostic tests (with constant vein access provided and indirect glycaemia control):

- prolonged fasting test (18-24 hours) with the intent of provoking hypoglycaemia,

- test with glucagon $(0.03 \mathrm{mg} / \mathrm{kg}$ of body mass $)$ - checking glycogen reserve, 
- leucine tolerance test - in case of leucine-sensitive hypoglycaemia suspicion,

- rastinon tolerance test - in the diagnosis of hyperinsulinism,

- functional tests assessing hormonal reserves of the pituitary gland.

For the assessment of pituitary hormone functions, including the assessment of growth hormone secretion, various tests are used, including adrenocorticotrophic hormone (ACTH) stimulation testing (Synacthen test). In suspected growth hormone deficiency, growth hormone (GH) dynamic stimulation testing or screening test of nocturnal GH secretion is used. Extensive coverage of diagnostic endocrine causes of hypoglycaemia in childhood has been recently reported Ghosh et al. [37]

In order to confirm or exclude congenital metabolic disorder it may be essential to conduct further investigations, hence it is advised to secure samples of blood and urine. Such samples should also be secured in the case of a patient's death. In the diagnosis of hyperinsulinaemic syndromes some modern imaging methods are also used [96-98].

\section{TREATMENT OF HYPOGLYCAEMIA}

Hypoglycaemia treating should be undertaken immediately when decreased blood glucose level is detected and in the case when performing the measurement is not possible - when the suspicion of such a state is made on the basis of clinical symptoms. The lack of arrangements for reasons of glucose level decrease does not justify disregarding the proper reaction. The treatment should consider providing a dose of glucose in the first place, so as to maintain homeostasis, no matter what the further diagnostic or therapeutic steps will be.

Symptomatic treatment is meant to temporarily rebalance the blood glucose level. It should be performed promptly after detecting a reduction of this level:

- Newborns without clinical symptoms: the aim is 2.8$11.1 \mathrm{mmol} / \mathrm{l}(50-200 \mathrm{mg} / \mathrm{dl})$ of glycaemia:

- If the glucose level is $<2.2 \mathrm{mmol} / \mathrm{l}(<40 \mathrm{mg} / \mathrm{dl})$ : if oral nourishing is possible, immediately provide glucose solution and afterwards formula or breastfeeding; if oral nutrition is not possible, begin parenteral rehydration.

- If the glucose level is $<1.1 \mathrm{mmol} / \mathrm{l}(<20 \mathrm{mg} / \mathrm{dl})$, intravenous rehydration with $10 \%$ glucose should be administered, with a dosage of $4-8 \mathrm{mg} / \mathrm{kg}$ of body weight $/ \mathrm{min}$, as in the case of newborns with clinical symptoms of hypoglycaemia.

- Newborns with clinical symptoms of hypoglycaemia:

- Immediately input IV bolus of $0.20 \mathrm{~g}$ glucose $/ \mathrm{kg}$ which is $2 \mathrm{ml} / \mathrm{kg}$ of $10 \%$ glucose solution within $1-2$ minutes (do not use 25 or $50 \%$ solutions).

- Continuation of intravenous infusion of 6-8 mg glucose $/ \mathrm{kg} / \mathrm{min}$ of 10 or $50 \%$ solution or $90-120 \mathrm{ml} /$ $\mathrm{kg} / 24$ hours of $10 \%$ solution.
- Small for gestational age infants (SGA) and those whose mothers had toxaemia or who were exposed to intrauterine hypoxia require glucose infusion with dose $>20 \mathrm{mg} / \mathrm{kg} / \mathrm{min}$. The treatment might be necessary within 2-4 weeks.

Recent studies suggest that treatment with dextrose gel is safe and effective and may support breast feeding [99]. Randomized tests are needed to determine optimal thresholds for intervention and treatment strategies. Dextrose gel is effective in the management of neonatal hypoglycaemia in the postnatal ward setting [100].

Glycaemia monitoring in newborns with treated hypoglycaemia:

- Measuring of serum glycaemia should be repeated every 1-2 hours if no clinical symptoms are stated.

- In newborns with clinical symptoms of hypoglycaemia, measurements should be undertaken every 20-30 minutes.

- If the blood glucose level remains below $40 \mathrm{mg} / \mathrm{dl}$, the infusion of glucose should be increased to $10-12 \mathrm{mg} /$ $\mathrm{kg} / \mathrm{min}$; if hypoglycaemia still persists, the treatment and diagnostic procedures should be immediately intensified.

The aim of the therapy is to achieve a glucose level of at least $45 \mathrm{mg} / \mathrm{dl}$ (2.5 mmol/). Glucagon (GlucaGen HypoKit) may also be used as a medication supporting the treatment of hypoglycaemia; it is applied at the dosage of $0.03-0.1 \mathrm{mg} / \mathrm{kg} / \mathrm{dose}$ IV or IM [101]. However, it should be taken into account that the use of glucagon in the case of lack of hepatic glycogen supplies would be ineffective, so there would not be a hyperglycaemic effect in the state of starvation, adrenal gland insufficiency, or in permanent hypoglycaemia.

\section{CONCLUSIONS}

Causative treatment depends on the type of disorder and is very heterogeneous and not always efficient. Early recognition and correction of hypoglycaemia are required so as to avoid severe brain damage. In the treatment, the pharmacotherapy is performed with usage of diazoxide and somatostatin analogues that inhibit insulin secretion $[49,102]$. Diazoxide is the first-line treatment, although not all patients will fully respond to it, because episodes of hypoglycaemia may persist and it entails unpleasant adverse effects. Sirolimus has reportedly been successful in treating children with severe diffuse hyperinsulinaemic hypoglycaemia $(\mathrm{HH})$, thus obviating the need for pancreatectomy [103]. If persisting hyperinsulinaemia is diagnosed in infants before the third month of life, surgical intervention may be necessary. Surgical exploration is usually undertaken among infants who do not achieve improvement due to pharmacological treatment. Mohnike et al. suggest long-lasting use of low doses of octreotide combined with subcutaneous infusions of glucagon as a prevention of severe hypoglycaemia ep- 
isodes [104]. Sometimes, however, surgical treatment is unavoidable [105].

\section{DISCLOSURE}

The authors declare no conflict of interest.

\section{REFERENCES}

1. Otto-Buczkowska E, Szirer G, Jarosz-Chobot P. [Glucose homeostasis in children. I. Regulation of blood glucose]. Przegl Lek 2001; 58: 20-24.

2. Halaby LP, Steinkrauss L. Hypoglycemia: Symptom or Diagnosis? J Pediatr Nurs 2012; 27: 97-99.

3. Hartmann AF, Jaudon JC. Hypoglycemia. J Pediatr 1937; 11: 1-36.

4. McQuarrie I. Idiopathic spontaneously occurring hypoglycemia in infants; clinical significance of problem and treatment. AMA Am J Dis Child 1954; 87: 399-428.

5. Alkalay AL, Flores-Sarnat L, Sarnat HB, et al. Plasma glucose concentrations in profound neonatal hypoglycemia. Clin Pediatr (Phila) 2006; 45: 550-558.

6. Hoe FM. Hypoglycemia in infants and children. Adv Pediatr 2008; 55: 367-384.

7. Stanley CA. Hypoglycemia in the neonate. Pediatr Endocrinol Rev 2006; 4 (Suppl. 1): 76-81.

8. Tam EW, Widjaja E, Blaser SI, et al. Occipital lobe injury and cortical visual outcomes after neonatal hypoglycemia. Pediatrics 2008; 122: 507-512.

9. Wintergerst KA, Buckingham B, Gandrud L, et al. Association of hypoglycemia, hyperglycemia, and glucose variability with morbidity and death in the pediatric intensive care unit. Pediatrics 2006; 118: 173-179.

10. Carstensen B, Lindström J, Sundvall J, et al. Measurement of blood glucose: comparison between different types of specimens. Ann Clin Biochem 2008; 45: 140-148.

11. Petersen JR, Graves DF, Tacker DH, et al. Comparison of POCT and central laboratory blood glucose results using arterial, capillary, and venous samples from MICU patients on a tight glycemic protocol. Clin Chim Acta 2008; 396: 10-13.

12. Faustino EV, Hirshberg EL, Bogue CW. Hypoglycemia in critically ill children. J Diabetes Sci Technol 2012; 6: 48-57.

13. Committee on Fetus and Newborn, Adamkin DH. Postnatal glucose homeostasis in late-preterm and term infants. Pediatrics 2011; 127: 575-579.

14. Dixon KC, Ferris RL, Marikar D, et al. Definition and monitoring of neonatal hypoglycaemia: a nationwide survey of NHS England Neonatal Units. Arch Dis Child Fetal Neonatal Ed 2017; 102: F92-F93.

15. Thompson-Branch A, Havranek T. Neonatal Hypoglycemia. Pediatr Rev 2017; 38: 147-157.

16. Le Compte A, Chase JG, Lynn A, et al. Blood glucose controller for neonatal intensive care: virtual trials development and first clinical trials. J Diabetes Sci Technol 2009; 3: 1066-1081.

17. Le Compte AJ, Lee DS, Chase JG, et al. Blood glucose prediction using stochastic modeling in neonatal intensive care. IEEE Trans Biomed Eng 2010; 57: 509-518.

18. Roth-Kleiner M, Stadelmann Diaw C, Urfer J, et al. Evaluation of different POCT devices for glucose measurement in a clinical neonatal setting. Eur J Pediatr 2010; 169: 1387-1395.

19. Beardsall K, Ogilvy-Stuart AL, Ahluwalia J, et al. The continuous glucose monitoring sensor in neonatal intensive care. Arch Dis Child Fetal Neonatal Ed 2005; 90: F307-F310.
20. Bridges BC, Preissig CM, Maher KO, et al. Continuous glucose monitors prove highly accurate in critically ill children. Crit Care 2010; 14: R176.

21. Iglesias Platas I, Thió Lluch M, Pociello Almiñana N, et al. Continuous glucose monitoring in infants of very low birth weight. Neonatology 2009; 95: 217-223.

22. Prabhudesai S, Kanjani A, Bhagat I, et al. Accuracy of a real-time continuous glucose monitoring system in children with septic shock: A pilot study. Indian J Crit Care Med 2015; 19: 642-647.

23. van Steen SC, Rijkenberg S, Limpens J, et al. The Clinical Benefits and Accuracy of Continuous Glucose Monitoring Systems in Critically Ill Patients-A Systematic Scoping Review. Sensors (Basel) 2017; 17: E146.

24. Steil GM, Langer M, Jaeger K, et al. Value of continuous glucose monitoring for minimizing severe hypoglycemia during tight glycemic control. Pediatr Crit Care Med 2011; 12: 643-648.

25. Alkalay AL, Sarnat HB, Flores-Sarnat L, et al. Population meta-analysis of low plasma glucose thresholds in full-term normal newborns. Am J Perinatol 2006; 23: 115-119.

26. Brand PLP. What is the normal range of blood glucose concentration in healthy term newborns? Arch Dis Child Fetal Neonatal Ed 2004; 89: F375.

27. McNamara PJ, Sharief N. Comparison of EML 105 and advantage analysers measuring capillary versus venous whole blood glucose in neonates. Acta Paediatr 2001; 90: 1033-1041.

28. Nicholl R. What is the normal range of blood glucose concentrations in healthy term newborns? Arch Dis Child 2003; 88: 238-239.

29. Rozance PJ, Hay WW. Hypoglycemia in newborn infants: Features associated with adverse outcomes. Biol Neonate 2006; 90: 74-86.

30. Hussain K, Sharief N. The inaccuracy of venous and capillary blood glucose measurement using reagent strips in the newborn period and the effect of haematocrit. Early Hum Dev 2000; 57: 111-121.

31. Balion C, Grey V, Ismaila A, et al. Screening for hypoglycemia at the bedside in the neonatal intensive care unit (NICU) with the Abbott PCx glucose meter. BMC Pediatr 2006; 6: 28.

32. Rosenthal M, Ugele B, Lipowsky G, et al. The Accutrend sensor glucose analyzer may not be adequate in bedside testing for neonatal hypoglycemia. Eur J Pediatr 2006; 165: 99-103.

33. Otto-Buczkowska E. [Disorders glucose homeostasis in the neonates and young infants. Part I. Hypoglycaemia]. Perinatol Ginekol 2006; 42: 33-39.

34. Schaefer-Graf UM, Rossi R, Buhrer C, et al. Rate and risk factors of hypoglycemia in large-for-gestational-age newborn infants of nondiabetic mothers. Am J Obstet Gynecol 2002; 187: 913-917.

35. Udani V, Munot P, Ursekar M, et al. Neonatal hypoglycemic brain - injury a common cause of infantile onset remote symptomatic epilepsy. Indian Pediatr 2009; 46: 127-132.

36. Stomnaroska O, Petkovska E, Jancevska S, et al. Neonatal Hypoglycemia: Risk Factors and Outcomes. Pril (Makedon Akad Nauk Umet Odd Med Nauki) 2017; 38: 97-101.

37. Ghosh A, Banerjee I, Morris AA. Recognition, assessment and management of hypoglycaemia in childhood. Arch Dis Child 2016; 101: 575-580.

38. Leiter SM, Parker VE, Welters A, et al. Hypoinsulinaemic, hypoketotic hypoglycaemia due to mosaic genetic activation of PI3-Kinase. Eur J Endocrinol 2017; 177: 175-186.

39. Stanley CA, Baker L. Hyperinsulinism in infants and children: diagnosis and therapy. Adv Pediatr 1976; 23: 315-355.

40. Hussain K, Bryan J, Christesen HT, et al. Serum glucagon counterregulatory hormonal response to hypoglycemia is blunted in congenital hyperinsulinism Diabetes 2005; 54: 2946-2951.

41. Ferrara CT, Boodhansingh KE, Paradies E, et al. Novel Hypoglycemia Phenotype in Congenital Hyperinsulinism Due to Dominant 
Mutations of Uncoupling Protein 2. J Clin Endocrinol Metab 2017; 102: 942-949.

42. Güemes M, Shah P, Silvera S, et al. Assessment of Nifedipine Therapy in Hyperinsulinemic Hypoglycemia due to Mutations in the ABCC8 Gene. J Clin Endocrinol Metab 2017; 102: 822-830.

43. Shah P, Rahman SA, Demirbilek H, et al. Hyperinsulinaemic hypoglycaemia in children and adults. Lancet Diabetes Endocrinol 2017; 5: 729-742.

44. De Leon DD, Stanley CA. Congenital Hypoglycemia Disorders: New Aspects of Etiology, Diagnosis, Treatment and Outcomes: Highlights of the Proceedings of the Congenital Hypoglycemia Disorders Symposium, Philadelphia April 2016. Pediatr Diabetes 2017; 18: 3-9.

45. Gilbert C. Investigation and management of congenital hyperinsulinism. Br J Nurs 2009; 18: 1306-1310.

46. Straussman S, Levitsky LL. Neonatal hypoglycemia. Curr Opin Endocrinol Diabetes Obes 2010; 17: 20-24

47. Maayan-Metzger A, Lubin D, Kuint J. Hypoglycemia rates in the first days of life among term infants born to diabetic mothers. Neonatology 2009; 96: 80-85.

48. Otto-Buczkowska E. [Maternal diabetes mellitus - risk factor for fetus and infant]. Ginek Prakt 2003; 11: 29-33.

49. Arnoux JB, de Lonlay P, Ribeiro MJ, et al. Congenital hyperinsulinism. Early Hum Dev 2010; 86: 287-294.

50. Dunne MJ, Cosgrove KE, Shepherd RM, et al. Hyperinsulinism in Infancy: From Basic Science to Clinical Disease. Physiol Rev 2004; 84: 239-275.

51. Huang Z, Li Y, Tang T, et al. Hyperinsulinaemic hypoglycaemia associated with a heterozygous missense mutation of R1174W in the insulin receptor (IR) gene. Clin Endocrinol (Oxf) 2009; 71: 659-665.

52. Martínez R, Fernández-Ramos C, Vela A, et al. Clinical and genetic characterization of congenital hyperinsulinism in Spain. Eur J Endocrinol 2016; 174: 717-726.

53. Snider KE, Becker S, Boyajian L, et al. Genotype and phenotype correlations in 417 children with congenital hyperinsulinism. J Clin Endocrinol Metab 2013; 98: E355-363.

54. Stanik J, Skopkova M, Brennerova K, et al. Congenital hyperinsulinism and glycogenosis-like phenotype due to a novel HNF4A mutation. Diabetes Res Clin Pract 2017; 126: 144-150.

55. Stanley CA. Perspective on the Genetics and Diagnosis of Congenital Hyperinsulinism Disorders. J Clin Endocrinol Metab 2016; 101: 815-826.

56. Vora S, Chandran S, Rajadurai VS, et al. Hyperinsulinemic Hypoglycemia in Infancy: Current Concepts in Diagnosis and Management. Indian Pediatr 2015; 52: 1051-1059.

57. Miron I, Diaconescu S, Aprodu G, et al. Diagnostic difficulties in a pediatric insulinoma: a case report. Medicine 2016; 95: e3045.

58. Padidela R, Fiest M, Arya V, et al. Insulinoma in childhood: clinical, radiological, molecular and histological aspects of nine patients. Eur J Endocrinology 2014; 170: 741-747.

59. Saneifard H, Khaleghnejad Tabari A, Kazemi Aghdam M, et al. Sporadic Insulinoma as a Rare Cause of Recurrent Hypoglycemia in Children. Case Rep Pediatr 2017; 2017: 4756793.

60. Glaser B. Familial Hyperinsulinism. In: Pagon RA, Bird TC, Dolan CR, Stephens K (Eds.). GeneReviews [Internet]. Seattle (WA): University of Washington, Seattle University of Washington, Seattle 1993-2017.

61. Palladino AA, Bennett MJ, Stanley CA. Hyperinsulinism in infancy and childhood: when an insulin level is not always enough. Clin Chem 2008; 54: 256-263.

62. de Lonlay P, Fournet JC, Touati G, et al. Heterogeneity of persistent hyperinsulinaemic hypoglycaemia. A series of 175 cases. Eur J Pediatr 2002; 161: 37-48.
63. Kapoor RR, Locke J, Colclough K, et al. Persistent hyperinsulinemic hypoglycemia and maturity-onset diabetes of the young due to heterozygous HNF4A mutations. Diabetes 2008; 57: 1659-1663.

64. Johnstone HC, McNally RJ, Cheetham TD. The impact of fasting and treatment omission on susceptibility to hypoglycaemia in children and adolescents with GH and cortisol insufficiency. Clin Endocrinol (Oxf) 2008; 69: 436-442.

65. Yeste D, Tomasini R, Dodino G, et al. Hypoglycaemia-insulin test: discordant growth hormone and cortisol response in paediatric patients regarding recovery from hypoglycaemia with or without oral glucose solution. Horm Res 2007; 67: 42-45.

66. Sreekantam S, Preece MA, Vijay S, et al. How to use a controlled fast to investigate hypoglycaemia. Arch Dis Child Educ Pract Ed 2017; 102: 28-36.

67. Keil MF, Bosmans C, Van Ryzin C, et al. Hypoglycemia during acute illness in children with classic congenital adrenal hyperplasia. J Pediatr Nurs 2010; 25: 18-24.

68. Chobot A, Otto-Buczkowska E. Glucose homeostasis from foetus through childhood. DDK/ECD 2011; 11: 29-38.

69. Crofton PM, Midgley PC. Cortisol and growth hormone responses to spontaneous hypoglycaemia in infants and children. Arch Dis Child 2004; 89: 472-478.

70. Das AM, Lücke T, Meyer U, et al. Glycogen storage disease type 1: impact of medium-chain triglycerides on metabolic control and growth. Ann Nutr Metab 2010; 56: 225-232.

71. Huidekoper HH, Visser G, Ackermans MT, et al. A potential role for muscle in glucose homeostasis: in vivo kinetic studies in glycogen storage disease type $1 \mathrm{a}$ and fructose-1,6-bisphosphatase deficiency. J Inherit Metab Dis 2010; 33: 25-31.

72. Rake JP, Visser G, Labrune P, et al. Guidelines for management of glycogen storage disease type I - European Study on Glycogen Storage Disease Type I (ESGSD I). Eur J Pediatr 2002; 161 (Suppl. 1): S112-119.

73. Soggia AP, Correa-Giannella ML, Fortes MA, et al. A novel mutation in the glycogen synthase 2 gene in a child with glycogen storage disease type 0. BMC Med Genet 2010; 11: 3 .

74. Crushell E, Treacy EP, Dawe J, et al. Glycogen storage disease type III in the Irish population. J Inherit Metab Dis 2010; 33 (Suppl. 3): S215-218.

75. Seigel J, Weinstein DA, Hillman R, et al. Glycogen storage disease type IIIa presenting as non-ketotic hypoglycemia: use of a newly approved commercially available mutation analysis to non-invasively confirm the diagnosis. J Pediatr Endocrinol Metab 2008; 21 : 587-590.

76. Correia CE, Bhattacharya K, Lee PJ, et al. Use of modified cornstarch therapy to extend fasting in glycogen storage disease types Ia and Ib. Am J Clin Nutr 2008; 88: 1272-1276.

77. Heller S, Worona L, Consuelo A. Nutritional therapy for glycogen storage diseases. J Pediatr Gastroenterol Nutr 2008; 47 (Suppl. 1): 15-21.

78. Eren E, Edgunlu T, Abuhandan M, et al. Novel fructose-1,6-bisphosphatase gene mutation in two siblings. DNA Cell Biol 2013; 32: 635-639.

79. Lebigot E, Brassier A, Zater M, et al. Fructose 1,6-bisphosphatase deficiency: clinical, biochemical and genetic features in French patients. J Inherit Metab Dis 2015; 38: 881-887.

80. Santer R, du Moulin M, Shahinyan T, et al. A summary of molecular genetic findings in fructose-1,6-bisphosphatase deficiency with a focus on a common long-range deletion and the role of MLPA analysis. Orphanet J Rare Dis 2016; 11: 44

81. Baker L, Winegrad AI. Fasting hypoglycemia and metabolic acidosis associated with deficiency of hepatic fructose-1,6-bisphosphatase activity. Lancet 1970; 2: 13-16. 
82. Otto-Buczkowska E, Jarosz-Chobot P, Szirer G. [Glucose homeostasis. II. Homeostasis disturbances - hypoglycemia in newborns and infants]. Przegl Lek 2001; 58: 79-81.

83. Hawkes CP, Stanley CA. 50 years ago in the Journal of pediatrics: Ketotic hypoglycemia. J Pediatr 2014; 164: 1310.

84. Huidekoper HH, Duran M, Turkenburg M, et al. Fasting adaptation in idiopathic ketotic hypoglycemia: a mismatch between glucose production and demand. Eur J Pediatr 2008; 167: 859-865.

85. Bodamer OA, Hussein K, Morris AA, et al. Glucose and leucine kinetics in idiopathic ketotic hypoglycaemia. Arch Dis Child 2006; 91: 483-486.

86. Cohen M, Zwiebel S, Jeanmonod R. Recurrent hypoglycemia in a toddler. Am J Emerg Med 2015; 33: 1847.e3-4.

87. Daly LP, Osterhoudt KC, Weinzimer SA. Presenting features of idiopathic ketotic hypoglycemia. J Emerg Med 2003; 25: 39-43.

88. Baruteau J, Levade T, Redonnet-Vernhet I, et al. Hypoketotic hypoglycemia with myolysis and hypoparathyroidism: an unusual association in medium chain acyl-CoA desydrogenase deficiency (MCADD). J Pediatr Endocrinol Metab 2009; 22: 1175-1177.

89. Kompare M, Rizzo WB. Mitochondrial fatty-acid oxidation disorders. Semin Pediatr Neurol 2008; 15: 140-149.

90. Maduemem KE. Medium-chain acyl-Coenzyme A dehydrogenase deficiency (MCADD): a cause of severe hypoglycaemia in an apparently well child. BMJ Case Rep 2016; 2016. pii: bcr2016217538.

91. Otto-Buczkowska E, Jarosz-Chobot P, Szirer G. [Hypoglycaemia as emergency state in childhood]. Med Intens Rat 2000; 3: 79-85.

92. Otto-Buczkowska E, Dryżałowski M. Alterations of blood glucose homeostasis in critically ill youngest patients. In: Otto-Buczkowska E (Ed.). Alterations in Glucose Homeostasis in Children, Adolescents and Young Adults - What's New? Nova Science Publishers; NY USA 2015: 119-129.

93. Srinivasan V, Agus MS. Tight glucose control in critically ill children - a systematic review and meta-analysis. Pediatr Diabetes 2014; 15: 75-83.

94. Hussain K, Sharief N. The inaccuracy of venous and capillary blood glucose measurement using reagent strips in the newborn period and the effect of haematocrit. Early Hum Dev 2000; 57: 111-121.

95. Otto-Buczkowska E, Jarosz-Chobot P, Szirer G. [Clinical and laboratory approach in childhood hypoglycaemia]. Med Metab 2000; 4: 68-73.

96. Burns CM, Rutherford MA, Boardman JP, et al. Patterns of cerebral injury and neurodevelopmental outcomes after symptomatic neonatal hypoglycemia. Pediatrics 2008; 122: 65-74.

97. Caksen H, Güven AS, Yilmaz C, et al. Clinical Outcome and Magnetic Resonance Imaging Findings in Infants With Hypoglycemia. J Child Neurol 2011; 26: 25-30.

98. Montassir H, Maegaki Y, Ogura K, et al. Associated factors in neonatal hypoglycemic brain injury. Brain Dev 2009; 31: 649-656.

99. Harding JE, Harris DL, Hegarty JE, et al. An emerging evidence base for the management of neonatal hypoglycaemia. Early Hum Dev 2017; 104: 51-56.

100. Ter M, Halibullah I, Leung L, et al. Implementation of dextrose gel in the management of neonatal hypoglycaemia. J Paediatr Child Health 2017; 53: 408-411.

101. Charsha DS, McKinley PS, Whitfield JM. Glucagon infusion for treatment of hypoglycemia: efficacy and safety in sick, preterm infants. Pediatrics 2003; 111: 220-221.

102. Flanagan SE, Kapoor RR, Mali G, et al. Diazoxide-responsive hyperinsulinemic hypoglycemia caused by HNF4A gene mutations. Eur J Endocrinol 2010; 162: 987-992.

103. Loke KY, Anjian AS, Yijuan YL, et al. Sirolimus therapy in a child with partially diazoxide-responsive hyperinsulinaemic hypogly- caemia. Endocrinol Diabetes Metab Case Rep 2016; 2016. pii: 16 0043.

104. Mohnike K, Blankenstein O, Pfuetzner A, et al. Long-term non-surgical therapy of severe persistent congenital hyperinsulinism with glucagon. Horm Res 2008; 70: 59-64.

105. Mazor-Aronovitch K, Landau H, Gillis D. Surgical versus non-surgical treatment of congenital hyperinsulinism. Pediatr Endocrinol Rev 2009; 6: 424-430. 